\title{
MU DANÇA COM MÁSCARAS DE INOVAÇÃO*
}

\author{
Vera Lucia Sabongi De Rossi ${ }^{* *}$ \\ O que muda na mudança, \\ Se tudo em volta é uma dança \\ No trajeto da esperança, \\ Junto ao que nunca se alcança? \\ (Carlos Drummond de Andrade, 1984) \\ Sente-se! Levante-se! Prepare-se para celebrar! \\ O Deus Mu dança. \\ $\mathrm{O}$ eterno Deus $\mathrm{Mu}$ dança. \\ Talvez com sua lança? \\ (C.Fonseca \& G.Gil, 1989)
}

\begin{abstract}
RESUMO: Pretendo refletir, a partir de fontes selecionadas, sobre algumas armadilhas conceituais decorrentes do par antigo/moderno (que posteriormente engendrou o inovador), no jogo dialético da modernidade, que revela o substrato temporal da mudança, envolta numa obra de falsos extremos. Destaco algumas de suas decorrências no processo modernizador da educação básica brasileira, em sua interação com a latino-americana, na busca de uma visão mais equilibrada do efeito homogeneizador das reformas educativas, tão caras às políticas de modernização conservadoras. Depois, apresento alguns resultados das pesquisas acerca dos fundamentos (des)mobilizadores de educadores nos processos de construção de projetos pedagógicos emancipadores e faço um breve alinhavo acerca do sentido único das políticas velozes que reprimem o tempo público de reflexão e de mudança.
\end{abstract}

Palavras-chave: Inovação/mudança. Modernização da educação básica. Reforma educacional. Projeto político-pedagógico.

* Agradeço a Carlos Jilmar Diaz Soler e Ana Regina Pinheiro pela leitura crítica.

** Professora do Departamento de Educação Conhecimento Linguagem e Arte (DELART), da Faculdade de Educação da Universidade Estadual de Campinas (UNICAMP), e membro do grupo de pesquisa "Memória, História e Educação". E-mail: derossi@mpc.com.br

Educ. Soc., Campinas, vol. 26, n. 92, p. 935-957, Especial - Out. 2005

Disponível em <http://www.cedes.unicamp.br> 


\section{CHANGES WITH A MASK OF INNOVATION}

ABSTRACT: Based on selected sources, I explore some conceptual traps stemming from the ancient-modern opposition (that latter yielded innovation) within the dialectical game of modernity. They reveal the temporal substratum of changes, enveloped in a work of false extremes. I then highlight some of their impacts on the modernizing process of the Brazilian basic education, and on its integration with Latino-America. This gives us a better balanced view of the homogenizing effect of the educational reforms, so dear to conservative modernizing policies. Next, I present some research results on the (de)mobilizing foundations of educators in the elaboration of emancipating pedagogical projects. I finally submit a brief outline of the quick policies that repress the public time of though and changes to show how one-way they are.

Key words: Innovation/changes. Modernization of basic education. Educational reforms. Political-Pedagogical Project.

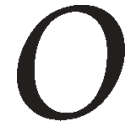

lamento profundo de Drummond e a insinuante celebração de Fonseca e Gil me permitem iniciar uma narrativa, mantendo ao mesmo tempo uma desconfiança nas evidências que se insinuam no gesto e no jogo da mudança e uma aposta no movimento incerto de tensões de múltiplas determinações que envolvem os sujeitos da escola, que tão astutamente movimentam seus projetos e sonhos, alargando espaços públicos de reflexão.

Depois de conviver com pessoas mais velhas, explicou Hobsbawn (1988), todo ser humano tem consciência do passado, definido como período anterior aos eventos registrados na memória de um individuo. $\mathrm{O}$ problema é analisar a natureza desse sentido do passado na sociedade e localizar suas inovações, mudanças e transformaçôes. $\mathrm{Na}$ devoção ao passado, acrescenta Le-Goff (1984), que é aquilo que a maior parte das sociedades considera como modelo do presente, há fendas através das quais se insinuam a inovação e a mudança. Só algumas seitas conseguem isolar-se e resistir totalmente à mudança, pois a ligação ao passado pode admitir novidades e transformaçōes.

Para Hobsbawn, o problema de se rejeitar sistematicamente o passado surge quando a inovação é identificada tanto como inevitável, quanto como socialmente desejável. Sabemos muito pouco sobre o processo que transformou tais palavras em sinônimos de melhor e de mais desejá- 
vel. Nesse sentido, Le-Goff (1984) produziu uma análise delicada, da qual vou reter alguns fragmentos, sobre as metamorfoses e significados da antítese antigo/moderno em contextos equivocados e complexos.

Do século $\mathrm{V}$ ao XIX o par antigo/moderno manteve o ritmo de uma oposição cultural que no século das luzes irrompeu na ribalta da cena intelectual sua polêmica mais célebre, que culmina com a obra-prima escrita por Condorcet (1793-1794), pouco antes de morrer, Esquisse d'un tableau des progrés de l'esprit humain, sobre a crença infinita no progresso e no tempo linear que privilegia sistematicamente o moderno. A transformação deu-se com o aparecimento do conceito de modernidade, ${ }^{1}$ que constitui uma reação ambígua à agressão do mundo industrial. Em meados do século XIX, com a revolução científico-tecnológica, a economia capitalista tornou-se global e o moderno foi excluído ou desvalorizado porque situado na esfera do progresso. Os modelos dos sistemas educativos únicos para todo o território do Estado nasceram da ideologia do industrialismo que levaram à criação das instituições políticas educativas inspiradas nos paradigmas industrial e militar, com raízes no modelo napoleônico de justiça e escola para todos. Com a introdução da modernidade no Terceiro Mundo, o ponto de vista dos modernos manifesta-se acima de tudo no campo da ideologia econômica e na construção da modernização, isto é, do desenvolvimento/subdesenvolvimento e da aculturação por imitação da civilização européia. Por meio de diversas formulas políticas e ideológicas há em geral dois desejos: encontrar no moderno que convém ao Terceiro Mundo - uma modernização seletiva e parcial, lacunar e empírica - e de procurar um equilíbrio entre tradição e modernização. O estudo do par antigo/moderno passa pela análise do momento histórico que segrega a idéia de modernidade e ao mesmo tempo a cria, para denegrir ou exaltar - ou simplesmente distinguir e afastar - uma antiguidade, que tanto destaca a modernidade para a promover como para a vilipendiar. Em síntese, é possível dizer que cada um dos termos e os seus correspondentes conceitos nem sempre se opuseram um ao outro, porque qualquer um dos dois pode ser acompanhado de conotações laudatórias, pejorativas ou neutras. Neste par, o principal problema está do lado do moderno, do novo (que posteriormente engendrou o inovador), que conduz o par e o jogo dialético da modernidade enquanto ruptura com o passado. O novo que implica nascimento, esquecimento, ausência de passado, começo puro, com o cristianismo assume o caráter quase sagrado de batismo. Com a Revolução Industrial, os tempos 
foram rodeados de novo, cuja frescura e inocência não tem, e de progressista, cujo dinamismo também não tem (Le-Goff, 1984). Hoje, o correlato do moderno não é mais o progresso, mas a evolução, o desenvolvimento socioeconômico. Hoje, no seu contraposto não está mais o antigo, mas o primitivo, o atrasado, o tradicional, que carregam o mesmo substrato temporal passado versus futuro.

É provável que parte importante da humanidade escapou até hoje à dialética dinâmica do par antigo/moderno e de seus concorrentes. Contudo, até a fase atual da modernização, parece que este não é caso da educação brasileira, quiçá nem latino-americana. Algumas questões de fundo apenas movimentam este texto, dada sua natureza de tema-problema, que não logro responder: Quais algumas das agências de produção de forças cognitivas e políticas que neutralizam instrumentos inovadores de análise e de mudança social? Quais as principais características do processo de modernização da educação básica brasileira em sua interação com a latino-americana? Existem potencialidades de inovação e de mudança nos projetos pedagógicos das escolas?

\section{Educação básica futuro-lógica}

Expectativas e ilusões marcam a política da educação na América Latina. Alguns slogans são recorrentes no imaginário social: Educar, peça chave para construir o futuro; Educação como prioridade nacional; Nunca como agora foi tão urgente a necessidade de delinear a educação básica; $A$ prescrição da subjetividade assegura o perfil docente do futuro...

A Conferência Mundial de Educação para todos (Tailândia, 1990), intitulada "Satisfação das Necessidades Básicas de Aprendizagem", parecia sugerir que estava superada a velha contradição cobertura-qualidade para introduzir a reconstrução do perfil docente na educação latino-americana do futuro. A chamada visão ampliada de educação comporta a qualidade da educação e um apego a noções-chave de competências básicas, necessidades básicas de aprendizagem e educação básica, sem historias nacionais. Todavia, existe uma diversidade de uso dos termos em cada país, com trajetórias, durações e estruturas diferenciadas.

A qualidade defendida pelo neoliberalismo é tecnocrática, gerencial, pragmática e se choca com uma tradição na qual a qualidade é uma concepção política, democrática e substantiva, erigida em uma história 
de lutas, dentro e fora do Estado, contra as desigualdades, as exclusōes e as discriminaçóes, e que procurou colocar à disposição dos jovens os recursos materiais e simbólicos dos que careceram de suas próprias vidas pelo desperdício desses mesmos recursos (Nunes, 2004, p. 98).

A inovação da educação básica associada à sociedade educadora latino-americana é um dos principais meios para redefinir novas funçōes globais e locais do público-privado e assegurar a revolução científicotecnológica-produtiva. O que está em jogo, alerta Gorz (2005), não é apenas o domínio que o capital até agora exerceu sobre os homens, mas a hegemonia do saber cientifico dominante, a racionalidade cognitivo-instrumental - que forneceu à técnica os instrumentos para a escravização dos homens. A economia do conhecimento é a principal força produtiva do capitalismo pós-moderno, centrado na valorização do imaterial. O homem carregando consigo seu próprio capital carrega igualmente uma parte do capital da empresa. A subjetividade é proscrita e os trabalhadores pós-fordistas devem entrar no processo de produção com toda sua bagagem cultural. Os pais e os educadores, o sistema de ensino e de formação também participam do general intellect, tornando acessíveis saberes e conhecimentos, capacidades de interpretação, intercompreensão e de comunicação constitutivas da cultura comum.

A Comissão Econômica para a América Latina e o Caribe (CEPAL) talvez seja o organismo regional das Naçôes Unidas que tem maior incidência para redefinição do modelo econômico. Em 1992, CEPAL-UNESCO elaboraram o documento "Educação e conhecimento: eixo da transformação produtiva com equidade". Dentre suas propostas encontra-se a tese de que a educação (entendida como manifestaçôes qualitativas) deve ser a base da principal inversão para o futuro desenvolvimento da potencialidade latino-americana. É relevante destacar do documento aspectos importantes de seus oito ensinamentos: o momento atual é uma nova oportunidade para recuperar o tempo perdido; ninguém inova à margem das tradiçōes; o consenso é essencial para qualquer proposta; é necessário dispor de certa capacidade de previsão; as mudanças institucionais são prioritárias; a avaliação dos resultados é indispensável para a mudança; o acesso eqüitativo à educação significa acesso aos conhecimentos socialmente significativos; os resultados da aprendizagem são prioritários; toda população deve poder manejar os códigos culturais básicos da modernidade - o conjunto de conhecimentos e destrezas necessários para participar da vida pública e desenvolver-se produtivamente. 
Neste documento, está a tradução em chave latino-americana de Jomtien, explica Martinez Boom (2004). Seus ensinamentos invadiram a literatura sobre economia e educação e serviram de base ao surgimento de novos modelos locais que guiaram a mudança da educação. Foram usados pelas agências internacionais, por investigadores, governos e alguns setores do magistério. A investigação educativa que produz seus objetos, definidos por certas necessidades políticas ou por impulso de uma nova tendência ou doutrina, mesmo com diferentes matrizes, ${ }^{2}$ contribuiu fortemente para instalar um conjunto de afirmaçôes circulares sobre os mesmos eixos. Recitam o mesmo discurso, gritam os mesmos slogans que explicam o aparecimento de temas prioritários, que na linguagem dos especialistas se denomina investigação relevante. Centenas de congressos, simpósios, artigos, revistas, livros e quase todos os governos e organismos internacionais (Banco Mundial e Instituição Internacional para Planificação Educativa) compartilham os mesmos programas e dedicam ingentes recursos a publicações destas novas prioridades. Um dos encontros que marcou significativamente a maioria dos estudos que circulam hoje foi o Seminário Regional de Investigação Educativa, realizado no Chile em $1993,{ }^{3}$ do qual surgiu a Propuesta de agenda de la investigacion latino-americana do ano 2000. As agências de financiamento contratam especialistas para que constatem as carências, proponham prioridades e soluçóes similares. Seus procedimentos e temáticas prioritárias converteram-se em eixos centrais da reforma educativa dos anos de 1990. Toda essa produção do conhecimento e de informação provém da maior fonte de categorias que justificam práticas de intervenção e de regulação dos processos educativos. Em muitos casos, as instituições profissionais, as organizações não-governamentais e os organismos internacionais cumprem funções de controle antes realizadas diretamente pelo Estado. Em outros casos, há fusão de ações entre instituições (dentro ou fora dos governos de Estados) que reproduzem teorias em inovações. Na verdade, hoje todos querem desmascarar o neoliberalismo, mas persistem algumas desconfianças: Será que o que os especialistas chamam de novas realidades e de desafios futuros da educação básica não significa a aceitação de construções sociais que são dadas pelas novas agências de controle? (Martinez Boom, 2004, p. 27-33).

Para evitar generalizações apressadas em torno de uma certa cumplicidade e de disputa pelo monopólio da visão de mundo que assessora políticas públicas, é importante retomar, de maneira breve, algumas pe- 
culiaridades da inovação e da mudança no passado brasileiro um pouco mais distante. Parece que neste tempo o emblema era outro.

\section{Vamos esquecer o passado}

"Educação nova", "Escola nova", "Campanha de renovação educacional", com o slogan "Nova educação para uma nova civilização em perpétua mudança" condensavam a polarização escola tradicional e moderna e o programa de reforma da sociedade pela reforma da escola. A política educacional, principalmente pós-1937, com a ditadura modernizadora do Estado Novo, integrava um projeto maior de crítica ao liberalismo, de políticas publicas dirigidas às áreas social e cultural. Trabalharam juntos os literatos egressos do Modernismo, intelectuais de todas as áreas do saber e de diversas matrizes ideológicas - socialistas, positivistas, integralistas e educadores - para levarem a cabo as reformas. Este movimento complexo de intelectuais no projeto de construção do Estado nacional, sem descartar a participação da Igreja, perpassou toda a América Latina.

Carvalho demonstrou que a obra de Fernando de Azevedo, o porta-voz dos renovadores da educação brasileira, interessado na legitimação do Estado Novo, cristalizou as representaçōes da educação, provocou um esvaziamento político das proposiçōes pedagógicas formuladas no debate da Escola Nova que coroou os anseios de modernização. Sua narrativa, construída pela polarização novo versus velho, produziu a inteireza do sentido unificador, o apagamento entre a intersecção do instituído e o projetado no campo educacional e construiu dois campos de investigação apartados: o da história das idéias e projetos pedagógicos e o da história da organização dos sistemas de ensino, tendo como eixo estruturador a história dos sistemas educacionais instituídos e das políticas que os instituíram. Desde os anos de 1970 até hoje, este tipo de leitura operou uma comunhão doutrinária modelar e conservadora que fez do dogma a forma privilegiada de apropriação das categorias marxistas, dentro dos cursos de pós-graduação em educação ${ }^{4}$ (Carvalho, 1998).

O estudo recente feito por Hilsdorf, Warde \& Carvalho (2004, p. 128) sobre a gênese do sistema educativo demonstrou que no campo da educação escolar existe um quadro rico e diversificado que indica a presença e o controle, mas não a exclusividade do poder público, o que tor- 
na insustentável a visão de Azevedo sobre o período pós-pombalino, que considerou como vazio, de decadência e de transição. A reforma de Azevedo ensaiou superar a dualidade do sistema escolar incorporando posições de Anísio Teixeira sobre a escola do trabalho, escola única. Não se trata de negar as mudanças introduzidas pelas reformas posteriores, mas de afirmar que a estrutura vertical e horizontal do sistema de ensino, que prevaleceu até recentemente, advém da Reforma Capanema.

Desde os tempos da Escola Nova até os atuais programas ligados à qualidade total, permanece o emblema Vamos esquecer o passado e apostar na fantasia do futuro harmonioso até o dia do juízo final, em que o farol do tempo consumado iluminará nossa compreensão. A educação destinada ao progresso fez da coincidência entre o novo e o alheio um valor absoluto. A idéia de modernidade e de desenvolvimento permitiu que os republicanos brasileiros, influenciados pelo positivismo, desprezassem a diversidade cultural com o critério que opunha modernos e atrasados, futuro e passado. As idéias de normalização e exclusão podem ser admitidas simultaneamente se pensarmos na possibilidade de existência de um sujeito - o publico escolar - que resistia à escolarização e um determinado tipo de Projeto de Escola (Cortez \& Souza, 2000 p. 44, 113).

No Brasil, os dispositivos legais criaram a seletividade, a discriminação e a rigidez com valores da velha ordem social aristocrática e oligárquica, que acabaram servindo de bússola orientadora da escolha da demanda social da educação. A escola não foi considerada como fator de mudança social e nem orientada pelas necessidades reais do desenvolvimento com revisão constante das naturais defasagens (Romanelli, 1978, p. 191).

A modernização dos governos militares, na tentativa de homogeneizar a heterogeneidade, separou o desenvolvimento econômico do social e manteve as propostas educacionais, que estiveram conectadas aos acordos MEC-USAID. Nos últimos cinco anos, houve um conjunto de alteraçōes estruturais que reforçaram privilégios e desigualdades de classe. $\mathrm{O}$ Brasil é o segundo país latino-americano, depois da Bolívia, em analfabetismo. A Constituição de 1988 foi a mais inovadora em relação à democratização da educação, mas os debates travados no Brasil nos quinze anos que tramitou a atual LDB acabaram por ter um peso político e social maior do que o próprio conteúdo da Lei.

Até hoje, foram aprovadas, em onze dos dezenove paises latinoamericanos, leis gerais da educação dos anos de 1990 (Brasil, Chile, 
Guatemala, Paraguai, Argentina, México, Bolívia, Equador, Colômbia e Panamá). Em outros países, definiram-se planos decenais ou projetos de reforma que não têm caráter de leis e são considerados referências fundamentais para a reorientação da ação educativa. Adicionalmente, em países como Uruguai, Equador, Costa Rica e Venezuela iniciou-se um processo de revisão da situação legal, gestionando acordos e normas parciais para ajustar as políticas educativas às novas tendências (Boom, 2004, p. 245). Todavia, a novas leis impulsionam, em alguns casos, transformações de fundo, dentre elas: novos parâmetros em relação ao público/privado, de direito à educação passa-se a serviço educativo, modifica critérios de avaliação; a gestão da escola-comunidade para materializar a privatização; implementação de uma nova estrutura dos sistemas educativos que incorpora o nível de educação geral básica com duração de nove anos.

Há dois modos de modernização educativa na América Latina, explica Martinez Boom (2004, p. 15): a escola expansiva, afirmada no ciclo quantitativo (1950-1970) e utilizada para consolidar os sistemas de educação de massa pelo paradigma do desenvolvimento econômico, e a escola competitiva, das necessidades básicas de aprendizagem impulsionadas pela reconversão da educação para refundar os sistemas de ensino. A modernização educativa compreende o conjunto de estratégias adotadas por distintas instâncias e centros de poder para racionalizar os sistemas educativos, a fim de que se ordenem em consonância com as mudanças dos objetivos políticos e proporcionem respostas flexíveis às pressóes econômicas das agências (inter) nacionais.

\section{Ritual litúrgico}

É sensível a insistência na função refundacional, da nova ordem de globalização das reformas, que tendem a manejar-se dentro do mesmo ritual que agrupa novos conceitos, nova normatividade, nova base jurídica, para dar resposta aos códigos da modernidade, incrementar a produtividade das economias e competitividade das naçóes. Parece que perdura o jogo do tempo fundador cristão - da pureza, do batismo - em novo estilo regulador, com novas especificidades do capitalismo flexível: contratos de trabalho flexíveis, salários de curto prazo, jornadas trabalho de longo prazo e rotatividade docente acelerada nas escolas.

A reforma significa reunir um conjunto de transformaçôes sociais para reduzir privilégios e desigualdades, mas com a escola competitiva 
passou a significar o inverso. Reformar gera sensação de movimento, que é apresentado como sinônimo de inovação e que parece provocar por si mesmo a mudança, a melhoria da oferta educacional e acaba justificando a existência de reformadores. O próprio conceito de reforma coloca um problema semântico, pois cobre ações de ordens e orientações político-ideológicas variadas. Há um ritual litúrgico que nos permite indagar se ao longo de tanto tempo terão deixado algo além de confusão e desmobilização. Seu mérito tem sido o de estimular o consenso em torno de certos ideais. No fundo, trata-se de uma concepção de inovação que é pouco custosa, rápida e requer poucos meios. Em educação sobrevive, em grande medida, uma forma de entender a mudança social não como gerada pelo processo de lutas e reivindicações históricas das organizaçōes sindicais e sociais envolvidas, mas a que se nutre de um certo messianismo e da mentalidade burocrática tradicional (Sacristán, 1996).

Os sindicatos e os docentes latino-americanos consideram que as reformas mantêm-se alheias as suas reivindicações históricas de lutas. Os processos de reforma coincidem com um aumento da conflitividade educativa, convertendo-a em protagonista central, mas a análise dos alcances dos processos de confronto implica levar em conta as instâncias políticas democráticas de deliberação, circulação de idéias e de projetos dos educadores (Gentili et al., 2004).

Apesar das inúmeras afirmações, cerceadas pelo determinismo das causalidades sistêmicas e pelos modelos e metros hegemônicos, é bastante difícil conhecer o alcance e os limites das reformas educacionais e das leis de educação nas escolas. Isto requer pesquisas, mas já despontam algumas boas pistas. O discurso neoliberal é sem dúvida um processo poderoso, mas não podemos esquecer, explica Nunes (2004, p. 98), que as políticas globalizadoras presentes em um mesmo quadro discursivo, com projetos semelhantes em vários paises, não são propriamente idênticas, são híbridas, pois não existe correspondência perfeita entre as reformas pretendidas e as executadas. Krawczyk \& Vieira (2003) perceberam que os resultados que norteiam a compreensão das mudanças educacionais latino-americanas não são os esperados por seus ideólogos. Apesar da unicidade das políticas educacionais vigentes, existe um distanciamento entre as diretrizes e intencionalidades expressas nos documentos oficiais e a realidade concreta nas escolas, suas formas culturais particulares de realização societária; de implantação dos sistemas educacionais e das interrelacões das distintas demandas com o Estado. Vinão Frago (1998) 
explicitou que teoria, legalidade e realidade escolar nem sempre coincidem, pois se influenciam reciprocamente. A escola gera uma cultura, condicionada e condicionante da realidade social, que é mais complexa e multiforme do que as regulações que imaginamos em linha reta.

Pela via da infidelidade normativa, explica Lima (2001), é possível perceber que entre a concepção da produção normativa e sua execução no contexto escolar existe um complexo processo de comunicação que não é necessariamente coincidente com a execução pelos destinatários de diferentes níveis hierárquicos. No caso da legislação, a infidelidade, voluntária ou não, é um fenômeno típico que pode se dar em oposição à conformidade normativa burocrática, quando os atores mantêm a fidelidade com seus objetivos, interesses e estratégias. A infidelidade nos permite questionar a chamada maior força dos aparelhos tecnocráticos que é sua capacidade de definir e impor normas, como afirmou Touraine (1981). A maior força dos atores, para além de sua capacidade de produção de regras, poderá ser a de submissão às normas, explorando as suas eventuais fontes de incerteza sobre o controle das quais se afirma um certo tipo de poder que toma por base o conhecimento e a competência (Lima, 2001, p. 65-66).

Um recente ensaio sobre a situação da educação básica na Espanha concluiu que a pressão sobre as tarefas do professor não procede das reformas educativas em curso e de suas implicaçóes. Os reformadores, em várias circunstâncias históricas, não suspeitaram das numerosas formas de resistência profissional nos seus programas de mudança. Existem relações de autonomia, interdependência e convergência entre a cultura empírica dos estudantes (guiadas pela lógica da razão prática), a cultura científica dos acadêmicos (regulada pelo logus dos discursos) e a cultura política dos gestores (determinadas por estratégias burocráticas de controle social). Apenas quando negociam com os educadores projetos inovadores é que se criam convergências interculturais. Contudo, as reformas dos últimos anos na Espanha quiseram em princípio utilizar o potencial dos movimentos de renovação pedagógica, que em parte foram neutralizados e absorvidos pelo sistema (Escolano, 2005).

\section{Projetos de Re-existências}

O que é considerado inovador no campo da lei e da reforma internacional dos anos de 1990? Os Proyetos Educativos del Centro (PEC) os Proyetos de la Instituición Escolar (PEI), como são chamados na Amé- 
rica Latina, ou os Projetos Político-Pedagógicos (PPP), como são chamados no Brasil. Não apenas pela via mais convencional dos currículos, mas pela via do PPP e da gestão escola-comunidade espera-se inovar as estratégias de controle da educação básica para implementar mudanças de fundo prioritárias - (auto)avaliação excludente, o auto-financiamento da gestão escola-comunidade, a partir do modo de produção da escola competitiva, fornecedora dos perfis profissionais para um novo tipo de civilização e de competidores, vulneráveis aos conflitos de valores insolúveis e ao consentimento às políticas de desemprego que embalam o regime planetário do lucro.

Nos anos de 1980/90, momento pós-ditatorial prolongado que afetou direta ou indiretamente boa parte da América Latina, a inovação e a mudança entraram como palavras de ordem no movimento políticopedagógico de múltiplas tendências e expressões nas diferentes áreas do conhecimento. Todavia, há uma distinção importante. $\mathrm{O}$ ppp inovador pode ser tomado como ação regulatória ou técnica quando é explicitada pelo caráter regulador da ciência conservadora, pela observação descomprometida, certeza ordenada, padronização, uniformidade, controle burocrático, mudança temporária ou parcial. A inovação emancipatória é produção humana alicerçada no caráter emancipador e argumentativo, repensa a estrutura de poder, as relaçôes sociais e seus valores. A elaboração do PPP sob a perspectiva da inovação emancipatória é um processo de vivência democrática entre os segmentos que compõem a comunidade escolar e acadêmica (Veiga, 2003).

Em artigos anteriores, tenho tentado refletir acerca dos fundamentos (des)mobilizadores dos PPP inovadores-emacipadores, mediados por gestôes colegiadas de educadores predominantemente progressistas, das escolas públicas brasileiras, ${ }^{5}$ iniciados antes da atual LDB. ${ }^{6} \mathrm{O}$ PPP emancipador (ou alternativo) é uma via privilegiada de acesso à cultura da escola, seus modos próprios de organização, transgressão e regulação da vida escolar, suas regras implícitas e explicitas, rotinas de trabalho, hierarquias, relações de afeto e de poder. A projet-ação é política e pedagógica para dar conta da organização espacio-temporal de todas as atividades (extra) escolares. No processo de estruturação do PPP para toda a educação básica está presente a sua essência pedagógica - (re)produção do conhecimento entrelaçado aos saberes docentes e discentes, concepção de educação, de currículo, objetivos educacionais e ideais emancipadores que permanecem como pano de fundo. A arte de projetar, especificar mediaçôes para transformar o real - 
sempre fugidio e sempre desejado -, busca assegurar a plena qualidade do processo de ensino-aprendizagem. O processo decisório da gestão do PPP assegura o conflito de idéias e de valores (o coração das relaçôes democráticas), bem como a interlocução permanente entre os colegiados do Conselho de Escola, APM, Grêmios estudantis e todos os sujeitos da escola-comunidade (sem esquecer das autoridades públicas). Implica planejamento e avaliação contínuos e sua implementação depende dos limites e das potencialidades humanas e materiais, seleção de critérios para alocação e distribuição de recursos. Por considerar os educadores como construtores de política, ao nível (in)formal, o projeto emancipador é local e universalista, em sua intenção e abrangência, pois a educação para a liberdade só se efetivará no processo de lutas sociais internacionalizadas quando todos os indivíduos tiverem condições de (auto) emancipação intelectual, política e econômica (De Rossi, 2004).

Comparando alguns resultados de pesquisas podemos aprender algumas lições.

Há inúmeros educadores anônimos que desenvolveram PPP inovadores de grande interesse nas escolas públicas brasileiras de diferentes tempos e espaços, mais contados do que registrados provavelmente por não constituírem temas relevantes, do ponto de vista das agências de produção de categorias já mencionadas. Saturados de ideologia autoritária e indignados com o dogmatismo, educadores progressistas tentaram reduzir algumas incertezas do futuro, com projetos que conseguiram entrever e vivenciar, mesmo com as névoas do presente. Propuseram-se a revisão dos processos educativos com pedagogias libertárias, principalmente freireanas e histórico-críticas (1970/90), com forte apelo político socialmente orientado (De Rossi, 1999, 2002, 2003).

Os educadores colombianos, no processo da construção dos projetos pedagógicos, têm atribuído novos sentidos para o processo de ensino aprendizagem, assegurado a pertinência do currículo e revisto os indicadores de avaliação como síntese dos ideais de compromisso com a transformação social. A análise dos projetos (mais recentes e os mais antigos) demonstra que educadores buscam superar a carência da qualidade de ensino, abrir espaços para oposições e dissensos, mas que por vezes os projetos têm sido pouco duradouros (Castillo, 1999; Cardenas, 1999).

Os educadores brasileiros também enfrentaram inúmeras dificuldades com o desdobramento dos conflitos intra e entre categorias, difi- 
culdades político-institucionais e econômicas. Todavia, a maior parte dos PPP locais, regionais, municipais - e mesmo os de porte nacionais (tais como LDB e PNE) que envolveram segmentos da sociedade brasileira - teve curta duração, foram excluídos, diluídos ou assimilados e descaracterizados pelo Estado. Diferente das propostas do Banco Mundial e da atual LDB, os PPP mais duradouros foram financiados pelos poderes públicos municipais ou estaduais, mantiveram certa autonomia pedagógica, mas não foram fragmentados por escola e sim entrelaçados aos movimentos sociais, sindicais e acadêmicos.

O tema dos Ppp emancipadores (antes e depois das leis da educação dos anos de 1990) permanece sendo eixo central da discussão relacionada com a concretização de uma educação de qualidade, para criação de espaços de gestão e de convivência democrática escola-comunidade. A projetualidade é constitutiva da forma política, mas existe uma tensão em ato entre a forma projetual e a autoconsciência do sujeito. $\mathrm{O}$ fortalecimento das subjetividades políticas nos casos brasileiro e colombiano deu-se com a criação de uma rede de comunicação, de sociabilidade e de troca de experiências significativas entre as diversas categorias do magistério e com a luta pela formação intelectual permanente que potencializa o educador para o processo de aprendizagem-ensino, para vencer a apatia e atuar junto aos demais movimentos sociais na definição de políticas educacionais (Martinez Pineda, 2005; De Rossi, 2005).

As políticas educativas não podem seguir desconhecendo expressões, saberes culturais, experiências e projetos dispersos em tradições e memórias de educadores em nossos sistemas educativos formais, como fatores determinantes para conhecer os limites e potencialidades das inovações e mudanças significativas para nossas comunidades.

As inovações que se introduzem no sistema formal de educação resultam de coalizões negociadas, explicita ou implicitamente, com os sujeitos da escola. As inovações e mudanças mais substantivas ocorreram ao longo da história pelas vias menos formais, na cultura escolar, no processo de construção de experiências e de projetos pedagógicos alternativos. Esse saber pedagógico informal atuou como tradição poderosa que muitas vezes ignorou reformas e passou por cima de intervenções administrativas (Escolano, 2005; Vinão Frago, 1998; Cortez \& Souza, 2000; Hilsdorf, Warde \& Carvalho, 2004; De Rossi, 2003).

A hipótese que subjaz ao resultado de amplo estudo comparado (Gallego, 2004) é que a América Latina ainda não encontrou um projeto 
educacional que aponte a integração continental e sua inserção como bloco no concerto mundial, só porque não procurou. Seus sistemas educativos partiram de paradigmas de outras latitudes, desperdiçando sua riqueza cultural, dispersa e mestiça. Seria importante pensar como continente, fortalecer-se por meio do intercambio continental para competir no processo de globalização com alguma vantagem.

Certamente, a pesquisa histórica comparada latino-americana, a metodologia que imuniza contra generalizações apressadas e que estimula a investigação da diferença e das semelhanças, tem um papel importante para avançar o debate, mas creio que não podemos pensar só como continente, mas como continente-mundo. Senão, corremos o risco de reproduzir e importar, pela via da rejeição ideológica e aceitação formal da visão eurocêntrica invertida, o mais contestável dos modelos que se converte em tropicocentrismo ou em latinocentrismo (empresto de Rouanet as expressóes). Isto pode reduzir a partilha de experiências de outros educadores de outros continentes que em sua maioria desconhecemos.

São bastante semelhantes as dificuldades de inovação entre educadores da América Latina, Austrália, Nova Zelândia, Reino Unido e América do Norte (Apple \& Beane, 2000) e Espanha: excessos idealistas, pragmáticos e fundamentalistas; pedagogias qualificadas pelo espontaneísmo ou pelo laissez-faire, que confundem autoridade com autoritarismo, democracia com democratismo; as críticas dos neoconservadores que afirmam que as pedagogias progressistas e inovadoras são causas de todos os males da escola atual. Quando se aproximam das inovações? Com a organização do conhecimento, as revisôes críticas dos clássicos, quando a pedagogia se aproxima de outros conhecimentos disciplinares e mantém relações teoria e prática, quando educadores assumem as incertezas do futuro sem abrir mão de princípios elementares da escola democrática e igualitária (Sebarroja, 2001).

$\mathrm{O}$ enfoque progressista da inovação tem rosto e nomes de pessoas conhecidas por seus escritos e por sua projeção pública. Alguns deles já adquiriram valor de clássicos e deram vida a uma pedagogia libertária, crítica, anti-repressiva, com sugestivas análises dialéticas nutrindo-se de impulsos utópicos. Dentre eles: Rousseau, Gramsci, Dewey, Freinet, Decroly, Piaget, Robin, Ferrer, Vigotski, Lipmann, Stenhouse, Piussi, Illich, Paulo Freire, Milton Santos e tantos outros espalhados por todos os cantos do mundo. 
Quando leio ou escuto histórias de experiências alternativas e de projetos emancipadores de diferentes países, não creio que os educadores envolvidos estejam dispostos a reproduzir regras, estimular competências e adequar a escola às leis do mercado. Ao contrário, mesmo na atualidade, há casos de projetos comprados, roubados, copiados e engavetados que podem oferecer indícios da seriedade e da desconfiança dos educadores diante do espetáculo da participação e autonomia outorgadas pela atual LDB. A re-existência dos educadores pode significar diferentes formas de manifestar suas tantas escolhas, suas recusas às tentativas de organização utilitária da vida escolar, seus ressentimentos em relação aos descaminhos do Projeto Fantasma, que no coração do liberalismo burguês traçou as diretrizes da escola pública democrática para todos, tão negligenciada por políticas publicas sociais durante tanto tempo.

Como bem definiu Cora Coralina, existir é uma maneira de resistir, de coexistir e de transistir. Ela própria elegeu um modo diferente de contar velhas histórias e percorreu a escalada da Montanha da Vida, removendo pedras e plantando flores. Lembram-se da Mestra Silvina, que mesmo no céu ainda tem nas mãos um livro de ouro e ensina a soletrar os anjos? Bença Mestra! Ainda temos muita lição para aprender e outras tantas para desaprender. Por exemplo, aquelas que tendem a nos impelir ao redemoinho conceitual da razão dualista desmobilizante, anulando a vontade de agir coletivamente em busca do bem comum. Senão, como restabelecer em educação o tráfego com a universalidade do humano? De Certeau (1995, p. 250), como sempre, tem palpites acerca do assunto:

Somos ricos em conhecimentos e métodos no que concerne às estruturas e bastante pobres quando se trata de analisar transformações em movimento, que inserem criaçôes nas aparentes coerências legais e contratuais, que alteram, corroem e mudam pouco a pouco o equilíbrio das constelaçóes sociais (...). A possibilidade implica que os sistemas não sejam mais pensados como objetos estáveis perante o olhar imóvel do saber. Os sistemas aparecem antes como estruturas em processo de deslocamento, como equilíbrio de forças em conflito. A própria ciência não é autônoma e participa de seus avatares. Isso requer uma retomada da dialética elaborada por e desde Marx (...). A inovação, que a modifica ao atravessá-la, produz efeitos de representação e transformações sociais. A análise e a prática da inovação nos espaços construídos não tocam no essencial, que é também o mais frágil: um desejo de viver, ao perder as seguranças que cada sociedade multiplica - uma loucura de ser. 


\section{Máscaras de inovação}

Algo nos impele para frente no processo de aceleração que decorre sem intervenção da vontade e da consciência. Tal processo pode ser o resultado de raivas, ressentimentos e medos profundos do mal-estar da civilização e da cultura modernas. A política, explica Negt \& Kluge (1999), tornou-se uma questão de velocidade e quem decide rapidamente consegue vantagens de legitimação e deixa para trás aquele que precisa de tempo para reflexão. É urgente pensar um conceito de política que não aposte na fuga dos acontecimentos para que os homens deitem raízes na experiência. Onde a ação política reprime o tempo público de reflexão, sob pressão de aceleração, amontoam-se problemas não resolvidos e acumulam-se inovaçōes interrompidas. Os projetos, conflitos, protestos e movimentos sociais que se abrem para a emancipação pressupõem um intercâmbio (que certamente não existe no país) entre as fontes da política e os seus resultados. Para evitar sensação de vertigens diante daqueles que justificam o fim do Estado, podem tranqüilizar-se, pois como afirma Moraes (2004), os Estados nacionais continuam fazendo política. E se continua a fazer política também no interior dos Estados nacionais.

A escola contemporânea - que é sempre ciência e política - está dividida por quatro aspectos, que ao longo dos anos se entrelaçaram de maneiras variadas em espaços diversos, que perduram como problemas abertos: oposição escola de massa e escola de elite; entre escola de cultura (desinteressada) e escola profissionalizante (orientada por um objetivo); entre escola livre (com liberdade de ensino, como instância de verdadeira cultura da escola) e escola conformativa (de papéis sociais e produtivos) (Cambi, 1999).

Através de diversas fórmulas ideológicas, o moderno e o inovador conduziram o par dialético da modernidade na ruptura com o passado. Desde as revoluçóes inglesa e francesa do XVIII, quando a modernidade deu vida ao projeto político e pedagógico e sua colocação no âmbito do Estado, o mito que foi radicalizado aos limites da projeção utópica foi aquele que indicou a educação como substituta da política para construir, com as famílias, o perfil do cidadão moderno para a sociedade livre. O reformismo, imerso no processo de modernização do Terceiro Mundo, operou entre conservadorismos e mudanças para refinar, pela via da escola, a normalização, seleção e exclusão sociais. 
A mudança se torna sua própria legitimação quando se ancora no sentido do passado transformado, confere Hobsbawn (1998). A maior parte da ação humana consciente constitui um vasto mecanismo para comparar constantemente passado, presente e futuro, pois as políticas públicas assim o exigem. Mas, quando a mudança política acelerar ou transformar a sociedade para além de um certo ponto, quando a inovação puder desencadear um processo de correção ou retificação, do triunfo da razão sobre o absurdo e do conhecimento sobre a ignorância, o passado deve cessar de ser o padrão do presente e se tornar uma máscara para a inovação. Mas a experiência básica dos últimos dois séculos foi a da mudança contínua que se deu à custa de considerável casuísmo e de um modo um tanto misterioso (Idem, ibid., 1998).

Quando a representação do tempo é a da projeção futuro-lógica, ela reforça o projeto de nação nunca alcançado, religiosamente re-projetado. A utopia deixa de ser hipótese e torna-se uma ucronia para cobrir o intervalo entre intenção, projeto, finalidade e execução. Neste raciocínio circular, algumas categorias tornam-se comuns a alguns progressistas de direita e de esquerda, que ampliam sua antiga função sacerdotal associada à forma moderna-projetual para estender suas formas de domínio e controle na construção dos projetos para esferas públicas (De Rossi, 2002). Um exemplo? Até hoje a educação básica, com garantia das condições de acesso e permanência de crianças e jovens e como direito de todos os cidadãos, permanece reprojetada por diferentes governos entoando o slogan da Educação básica do futuro. Explica Hobsbawn (1998, p. 29-54):

Dizer que as análises das tendências de mudança social devem ser formuladas como proposiçôes preditivas verificáveis demonstra gentileza para com nossos filhos e netos, mas descortesia para os pobres Vico, Marx, Max Weber e, de quebra, Darwin, porque isso restringe o escopo da análise social e interpreta mal a história, cuja essência é estudar as transformações complexas ao longo do tempo (...). Para adaptar a frase de Auguste Comte, savoir não é prévoir, mas prévoir é parte do savoir.

Ou ainda, como sugere Benjamim (1985), é preciso introduzir uma transformação que não mais se faça plena de futuro, mas do presente, não mais do homem, mas do ser dos indivíduos; abrir caminho para uma política que saiba finalmente interpretar o potencial libertador contido na perda do sentido da História. Heródoto de Alicarnasso realizou uma mudança epistemológica substancial. Para ele, a eternidade só é pronunciável 
como construção de homens históricos que manifestam seu desejo de fuga da temporalidade. Ele quis produzir o conhecimento da mudança, uma descrição do transcurso dos homens finitos em sua experiência de finitude, que ele paradoxalmente considerou o único apreensível e cognoscível. De certa forma, o tempo dos Annales é uma continuidade do projeto de Heródoto contra a atemporalidade da estrutura social. Uma desaceleração cautelosa e uma reação à aceleração revolucionária baseada em um conhecimento especulativo do sentido da história (Reis, 1998, p. 28-34).

$\mathrm{O}$ moderno não está de modo algum associado à moda, pois moda e moderno ligam-se ao tempo e ao instante, misteriosamente ligados ao eterno, imagens móveis da imóvel eternidade, diz Lefevre, comentando Baudelaire. O moderno tende a valorizar o novo pelo novo, esvaziar o conteúdo da obra. Sua novidade não está determinada pela análise, mas pelo poder político, econômico, social e da pedagogia. Todavia, esse período que se quer totalmente novo deixa-se obcecar pelo passado, memória e história. Mas a modernidade não funciona sem um certo utopismo. $\mathrm{O}$ excedente utópico do projeto modernizador do iluminismo está contido nas últimas linhas de Condorcet, antes de sua morte: "Chegará pois este momento em que o sol só iluminará sobre a terra dos homens livres, sem reconhecerem outra autoridade que a da razão; em que os tiranos e os escravos, os fanáticos e seus instrumentos hipócritas e estúpidos só existirão na história e no teatro". Entretanto, a modernidade funcional (da eficácia) progride até hoje a largos passos, pois a tirania domina metade do gênero humano e a pobreza assola três quartos da humanidade. A modernidade utópica alimenta-se dos seus sonhos de autonomia irrealizados (na Ilustração, no liberalismo e no socialismo), mas ainda precisamos deles (Rouanet, p. 181). Os pioneiros da inteligência artificial (Minsky, Moravec, Kurzweil e outros) não ocultam seu desprezo pela máquina de carne humana, o fim do gênero humano está programado e a ciência parece realizar seu projeto original de se emancipar do gênero humano, diluído em dígitos e dissolvidos no universo (Gorz, 2005, p. 13).

As ambigüidades da modernidade jogam principalmente em relação à revolução. Como disse Lefevre (1962) a modernidade é a sombra da revolução, o seu dispersar e por vezes a sua caricatura. Essa ruptura dos indivíduos e das sociedades com o passado, esta leitura não revolucionária, mas irreverente da história, talvez por estar impregnada de vida cultural e quotidiana, constituem também, e paradoxalmente, um instrumento de adiamento, de mudança e de transformação (Le-Goff, 1984, 
p. 381). O conceito polêmico de modernidade, por ser um projeto inacabado, está em contradição com a situação concreta na qual se erige e ao mesmo tempo se contrapõe (Ortiz, 1988).

\title{
A eterna sensibilidade de Sergio Buarque de Hollanda, em Raízes do Brasil, nos permite enveredar em algo muito peculiar de Nossa Revolução:
}

\begin{abstract}
A forma visível dessa revolução não será, talvez, a das convulsões catastróficas, que procuram transformar de um mortal golpe, e segundo preceitos de antemão formulados, os valores longamente estabelecidos. É possível que algumas de suas faces culminantes já tenham sido ultrapassadas, sem que possamos avaliar desde já sua importância transcendente (...). Podemos ensaiar a organização da nossa desordem segundo esquemas sábios de virtudes provadas, mas há de restar um mundo de essências mais íntimas que, esse, permanecerá sempre intacto, irredutível e desdenhoso das invenções humanas (...). As formas superiores da sociedade emergem continuamente das necessidades específicas e jamais de escolhas caprichosas. Há, porém, um demônio pérfido e pretensioso, que se ocupa em obscurecer aos nossos olhos estas verdades singelas. Inspirados por ele, os homens se vêem diversos do que são e criam novas preferências e repugnâncias. É raro que sejam das boas. (Hollanda, 1973, p. 142)
\end{abstract}

\section{Recebido e aprovado em agosto de 2005.}

\section{Notas}

1. A modernidade encontrou seu teórico em Henri Lefebvre, que distinguiu modernidade de modernismo. O segundo quer dizer arrogância e certeza, o primeiro interrogação e reflexão crítica, inacabado, irônico com tendência para realizar o programa delineado pelo Romantismo. Assim se reencontra o conflito antigo/moderno a assumir, nesta longa duração, a sucessão da oposição conjuntural clássico/romântico, na cultura ocidental.

2. Para a interpretação da realidade educativa latino-americana atual, predominam duas chaves de leitura a crítica (marxista, neomarxista) e dentre seus principais representantes encontram-se Apple, Carnoy, Escudero, Torres e Gentili; e da visão realista, Rama, Corragio e Tedesco, um dos principais autores do documento Educacion y conocimiento. Alguns participantes destas posturas foram protagonistas das reformas educativas, colaboraram com agências educativas na definição, execução e avaliação de políticas, ocupando cargos de direção e gestão (Martinez Boom, 2004).

3. FLACSO, PIIE, CIDE, REDUC, PROMEDLAC.

4. Bruno Bontempi Jr. (2002) analisou 146 dissertaçôes e teses produzidas nos programas de pós-graduação em educação no Brasil de 1972-1988 e constatou que predomina o aporte marxista-reprodutivista, que tem como principais interlocutores obras de sociologia ou de filosofia de viés liberal. $\mathrm{O}$ uso da história que unifica os diferentes paradigmas.

5. Foram analisadas as peculiaridades e semelhanças entre dois amplos ppp regionais de dois estados brasileiros, que envolveram mais de cinco mil professores da rede pública de en- 
sino: um de Campinas (SP) e mais oito municípios; Santa Terezinha e São Felix do Araguaia (MT); e dois ppp de escolas: CEFAM-Campinas (SP) e do Colégio de Aplicação da Universidade Federal do Maranhão (UfmA) (Santos, 2004).

6. As pesquisas empíricas e análises dos PPP pós-LDB estão em curso.

\section{Referências bibliográficas}

APPLE, V.M.W.; BEANE, J.A. Escolas democráticas. Porto: Porto, 2000. BENJAMÍN, W. Magia e técnica, arte e política. São Paulo: Brasiliense, 1985.

BONTEMPI JR., B. Historia da educação brasileira: o terreno do consenso. In: FreItas, M.C. (Org.). Memória intelectual da educação brasileira. 2.ed. Bragança Paulista: EDUSF, 2002.

CAMBI, F. História da pedagogía. São Paulo: unesp, 1999.

CÁRDENAS, E.T. Entre la seducción y la locura. In:VIDA de maestro: la inovación em la escuela; una passion hecha proyeto. Santa Fe, Colômbia: IDEP, 1999.

CASTILLO, I.R. La innovación educativa: la existencia pedagogica. In: VIDA de maestro: la inovación em la escuela; una passion hecha proyeto. Santa Fé, Colômbia: IDEP, 1999.

CARVALHO, M. A configuração da historiografia educacional brasileira. In: Freitas, M.C. (Org.). Historiografia brasileira em perspectiva. São Paulo: Contexto, 1998.

CONDORCET. Esquisse d'un tableau historique des progrès de l'ésprit humain. Paris: Editions Sociales, 1966.

CORAlinA, C. Poemas dos becos de Goiás e estórias mais. São Paulo: Global, 2003.

CORTEZ, M.C.; SOUZA, C. Escola e memória. Bragança Paulista: EDUSF, 2000.

DE CERTEAU, M. A cultura no plural. Campinas: Papirus, 1995.

DE ROSSI, V.L.S. Gestão de educadores progressistas. Pro-Posições, Campinas, v. 10, n. 29, p. 82-94, 1999. 
DE ROSSI, V.L.S. Dificultades proyetivas para los educadores y el estigma de la desilusion: un interes político? In: CASTRO, I. (Coord.). Visiones latino-americanas. México: Playa y Valdes, 2002.

DE ROSSI, V.L.S. Projetos político-pedagógicos emancipadores: histórias ao contrário. Cadernos Cedes, Campinas, v. 23, n. 61, p. 319-337, dez. 2003.

DE ROSSI, V.L.S. Gestão do projeto político-pedagógico: entre corações e mentes. São Paulo: Moderna, 2004.

DE ROSSI, V.L.S. La dimension político-afectiva de la gestion democrática de las escuelas publicas. In: Herrera, M.C.; Cardenas, Y. (Coord.). $I V$ Encuentro Internacional de Investigadores de la red educación, cultura y politica en America Latina. Bogotá: UPN, 2005.

ESCOLANO, A.B. Las culturas de la escuela em España. Pro-Posições, Campinas, v. 16, n. 46, p. 41-64, 2005.

GALLEGO, A.A. Los sistemas educativos en America latina. In: GARCES, O.L.Z.; SAUTer, G.O. (Comp.). Modernização de los sitemas educativos iberoamericanos. Bogotá: UPN, 2004. t. 2.

GENTILLI, P. et al. Reforma educativa y luchas docentes en America Latina. Educação \& Sociedade, Campinas, v. 25, n. 89, p. 1251-1274, set./dez. 2004.

GORZ, A. O imaterial. São Paulo: Annablume, 2005.

HILSDORF , M.L. et al. Apontamentos sobre a história da escola e do sistema escolar no Brasil. Gênesis y desarrollo de los sistemas educativos iberoamericanos. Bogotá: Magistério, 2004. t.1.

HOLLANDA, S.B. Raizes do Brasil. 7. ed. Rio de Janeiro: Jose Olympio, 1973.

HOBSBAWN, E. Sobre história. São Paulo: Cia das letras, 1998.

KRAWCZK, N.R.; VIEIRA, V.L. Estudos comparados sobre política educacional da América Latina. In: KraWCZCK, N.R.; WanderLeY, L.E. (Org.). América Latina: Estado e reformas. São Paulo: Cortez, 2003.

LIMA, L. A escola como organização educativa. São Paulo: Cortez, 2001.

LE GOFF, J. Memória-história. Portugal: Einaudi, 1984. v.1. 
MARTINEZ BOOM, J. De la escuela expansiva a la escuela competitiva. Bogotá: Anthropos, 2004.

MARTINEZ PINEDA, M.C. Redes y subjetividades politicas: modos de agenciamento. In: Herrera, M.C.; Cardenas, Y. (Coord.). IV Encuentro Internacional de Investigadores de la red educación, cultura y politica en America Latina. Bogotá: UPN, 2005.

MORAES, R.C.C. Globalização e políticas públicas: vida paixão e morte do Estado Nacional? Educação \& Sociedade, Campinas, v. 25, n. 87, p. 309-335, 2004.

NEGT, O.; KLUGE, N. O que há de politico na política? São Paulo: UNESP, 1999.

NUNES, C. Las leyes nacionales de educación en la sociedad brasileña desde los anos sesenta a los noventa. In: Garces, O.L.Z.; SaUter, G.O. (Comp.). Modernización de los sitemas educativos ibero-americanos. Colômbia: Magisterio, 2004. t. 2.

ORTIZ, R. A moderna tradição brasileira. São Paulo: Brasiliense, 1988.

REIS, J.C. Os Annales: a renovação teórico-metodológica e utópica do tempo histórico. In: Saviani, D.; Lombardi, J.C. (Org.). História e história da educação. Campinas: Autores Associados, 1998.

ROMANELLI, O. Historia da educação no Brasil. Petrópolis: Vozes, 1978.

SACRISTAN, G. Reformas educacionais: utopia, retórica e pratica. In: Silva, T.T. (Org.). Escola S.A. Brasília: CNTE, 1996.

SANTOS, S.R.R. Gestão colegiada e projeto político pedagógico: COLUN São Luis, MA. 2004. Tese (doutorado) - Faculdade de Educação da Universidade Estadual de Campinas.

SEBARROJA, J.C. El profesorado y la inovación educativa. In: SACRISTÁN, G. (Coord.). Los retos de la enseñanza publica. Madrid: Akal, 2001.

VEIGA, I.P.A. Inovações e projeto político-pedagógico: uma relação regulatória ou emancipatória? Cadernos Cedes, Campinas, v. 23, n. 61, p. 267-283, dez. 2003.

VINÃO FRAGO, A. Por uma historia de la cultura escolar. In: Culturas e civilizaciones. Espanha: SPIC, 1998. 